\title{
General versus executive cognitive ability in pupils with ADHD and with milder attention problems
}

This article was published in the following Dove Press journal:

Neuropsychiatric Disease and Treatment

25 January 2013

Number of times this article has been viewed

\section{Ulla Ek'}

Joakim Westerlund ${ }^{2}$

Elisabeth Fernell ${ }^{3}$

'Department of Special Education, ${ }^{2}$ Department of Psychology,

Stockholm University, Stockholm, ${ }^{3}$ Gillberg Neuropsychiatry Centre, Sahlgrenska Academy, University of Gothenburg and the Research and Development Centre, Skaraborg Hospital Skövde, Sweden
Correspondence: Ulla Ek

Department of Special Education,

Stockholm University,

I069| Stockholm, Sweden

Email ulla.ek@specped.su.se
Background: The aim of this study was to analyze two main types of cognitive domains in school children with different types and severities of attention-related problems. The cognitive domains examined were general cognitive ability and executive abilities.

Methods: Three different clinical samples of pupils with school problems were analyzed to assess their cognitive Wechsler Intelligence Scale for Children profiles. In particular, the general cognitive ability index and the executive markers (ie, verbal memory index and processing speed index) were of interest. Of the total sample $(n=198)$, two main groups were contrasted; one met the full criteria for attention deficit hyperactivity disorder (ADHD)/subthreshold ADHD, and one was comprised of those with milder attention problems, insufficient to meet the criteria for ADHD/subthreshold ADHD.

Results: It could be demonstrated that both groups had a significantly higher score on the general cognitive ability index than on measures of working memory and processing speed. This difference was more pronounced for boys.

Conclusion: These types of cognitive differences need to be considered in children with different kinds of learning, behavior, and attention problems; this is also true for children presenting with an average general intelligence quotient and with milder attention problems. Current educational expectations are demanding for children with mild difficulties, and such cognitive information will add to the understanding of the child's learning problems, hopefully leading to a better adapted education than that conventionally available.

Keywords: working memory, processing speed, children, learning and attention problems, attention deficit hyperactivity disorder, subthreshold

\section{Introduction}

The intelligence quotient (IQ), in particular the verbal IQ, is strongly related to academic achievement, ${ }^{1-4}$ and specific subsets of cognitive factors are also of importance. Geary ${ }^{5}$ followed the mathematics and reading achievements of children from grades 1 to 5 and found that working memory and processing speed contributed above and beyond the contribution of general intelligence. Poor working memory and slow processing speed are commonly found in children with a variety of developmental disorders, and have been singled out as "important neurocognitive factors". ${ }^{6}$ These factors reflect capacities that are sensitive to neurological deficits and are keystones in executive functions, that include components of attention, reasoning, planning, inhibition, focus shift, overview, and working memory. ${ }^{7-9}$

Low processing speed and poor working memory are reported in children with autism spectrum disorders, ${ }^{10}$ in children with language impairment, ${ }^{11}$ and in individuals 
with borderline intellectual functioning (slow learners). ${ }^{12}$ Alloway ${ }^{12}$ compared working memory and other executive function measures in children with borderline intellectual functioning (IQ 70-85) with those in children with IQ > 95, and found that students with borderline intellectual functioning had a highly distinct profile characterized by deficits in working memory and other executive functions. The same has also been found in children with intellectual/learning disability. ${ }^{13}$ Thus, it seems that processing speed and working memory are closely connected and of importance in the process of learning to read. Reading problems in children with ADHD were studied by Jacobson et al, ${ }^{14}$ who reported that processing speed deficits affected reading efficiency and that children with ADHD who decode words accurately can still have inefficient reading fluency that will further affect cognitive processes. Katz et $\mathrm{al}^{15}$ studied older adolescents with ADHD and reading disorders and compared the cognitive results with those having ADHD alone. Their results supported the hypothesis that those with both ADHD and reading problems had more difficulties with processing speed and working memory than those who had only ADHD. Working memory has also been found to be linked to outcome in mathematics. ${ }^{5,16}$

The data of interest for the present study were originally collected from three different studies, all addressing cognitive factors in relation to clinical presentations of learning and attention problems or disorders. We found very similar cognitive profiles across clinically defined groups and, in accordance with other studies, ${ }^{17}$ discovered that low working memory capacity and slow processing speed were not limited to attention disorders such as ADHD. An emerging hypothesis for the present study was that there are certain common cognitive profiles in pupils who present with learning, behavior, and attention difficulties during the school years, irrespective of whether they meet full criteria or not for an established diagnosis.

\section{Materials and methods}

In the present study, data from three previously reported samples were collapsed to create a single dataset: a population-based group of children, aged 10-11 years, who had been screened as positive for attention, behavior, and/ or learning problems $(n=144) ;{ }^{18}$ a representative group of teenagers aged 16-17 years, who had had language impairment and had attended special preschools $(\mathrm{n}=13) ;{ }^{19}$ and a group of teenagers aged 16-19 years who had not been able to complete compulsory elementary school $(n=45)^{20}$ and were therefore attending a school in a special program with the intention of attaining the required goals. The collapsed group consisted of 202 pupils. The three samples of children and adolescents described above represent a heterogeneous population, but have, as a common denominator, developmental problems of learning, behavior, and attention of varying degrees of severity. All children/adolescents had been clinically assessed and they had all had a full cognitive and pediatric/neuropediatric assessment, which included obtaining reports from parents and/or teachers.

\section{Cognitive assessment}

The Wechsler Intelligence Scale for Children (WISC) III ${ }^{21}$ had been used in all individuals. At the time of the first data collection, ${ }^{18}$ WISC IV had not been introduced in Sweden yet. At the time of the second ${ }^{19}$ and third ${ }^{20}$ data collections, WISC IV had been introduced, but the norms were not considered to be sufficiently reliable. WISC is made up of 13 subtests designed to measure various aspects of intelligence. It yields a full scale IQ, based on ten subtests, a verbal IQ, and a performance IQ. The verbal IQ is based on five subtests, reflecting vocabulary, common knowledge and information, logical verbal ability and practical reasoning, ability to make analyses and draw conclusions, and mathematical knowledge. The subtests are: information, similarities, vocabulary, comprehension, and arithmetic. The performance IQ is based on five subtests, intended to measure spatial thinking, processing speed, and various aspects of nonverbal reasoning and intelligence. The subtests are picture completion, coding, picture arrangement, block design, and object assembly.

In addition, four Kaufman indices can be computed: verbal comprehension index (based on information, similarities, vocabulary, and comprehension); perceptual organization index (based on picture completion, picture arrangement, block design, and object assembly); freedom from distractibility index (based on arithmetic and digit span); and processing speed index (based on coding and symbol search). The freedom from distractibility index is a measure of verbal working memory and requires the ability to focus and pay attention. The 13th subtest, ie, mazes, is not included in any of the indices or the IQ scales.

Complete WISC data were obtained for 198 pupils (128 boys and 70 girls). A full scale IQ of $\leq 70$, between 71 and 84 , and $\geq 85$ had been observed in 34 (18\%), 52 (26\%), and $112(56 \%)$ of the youngsters, respectively.

The general ability index was developed by Prifitera et $\mathrm{al}^{22}$ for use with the WISC III in order to provide additional flexibility in describing a broad intellectual ability. The WISC III general ability index provides a 
measure of general cognitive ability based on eight subtests: information, similarities, vocabulary, comprehension, picture completion, picture arrangement, block design, and object assembly, ie, the subtests comprising the verbal comprehension and the perceptual organization indices. Thus, it does not include the influence of arithmetic or coding required to obtain the full scale IQ.

The WISC III freedom from distractibility index and processing speed index reflect executive functions. The subtests that comprise these indices measure verbal working memory, set shifting, attention, graphomotor, and processing speed abilities.

\section{Neurodevelopmental assessment}

All pupils had varying degrees of learning problems and had been individually assessed by teams who were specialized in neurodevelopmental disorders. The evaluations had been based on information from parents, school health staff/ teachers, and questionnaires. ADHD had been determined according to DSM-IV (Diagnostic and Statistical Manual of Mental Disorders, Fourth Edition) criteria ${ }^{23}$ unless a pupil already had an established diagnosis of ADHD made by a specialized pediatric or psychiatric team on an earlier occasion. Subthreshold ADHD had been determined to be when the pupil met 4-5 of the nine DSM-IV criteria in the domains of inattention and/or hyperactivity/impulsivity. ${ }^{24}$ The criteria for ADHD $(\mathrm{n}=58)$ or subthreshold ADHD $(\mathrm{n}=10)$ had been met in a total of 68 pupils ( 48 boys and 20 girls). The remaining 130 individuals ( 80 boys, 50 girls) comprised children who did not meet the criteria for ADHD or subthreshold ADHD, but had milder attention-related problems.

Both groups included children who, in addition to attention-related problems, had a diagnosed mild intellectual disability and/or had been diagnosed with an autism spectrum disorder. In the group of 68 children with ADHD/ subthreshold ADHD, two had intellectual disability and four had autism spectrum disorder. The corresponding numbers in the group of 130 pupils with milder attention problems were seven and six, respectively. The mean ( \pm standard deviation) total IQ was similar in the two groups, at $86.90 \pm 14.54$ for those with ADHD/subthreshold ADHD and at 85.52 \pm 20.08 for the group with milder learning and attention problems $\left(t_{196}=-0.50, P=0.616\right)$

\section{Statistical analysis}

Three indices were computed: the general ability index, calculated as the average of the verbal comprehension and perceptual organization indices; the freedom from distractibility index, based on the arithmetic and the digit span subtests; and the processing speed index, based on the coding and symbol search subtests. Two separate $2 \times 3$ analyses of variance with the type of index (ie, general ability index, freedom from distractibility index, and processing speed index) as a within-subject factor and the index score as the dependent variable were performed, ${ }^{1}$ one with gender as a betweensubject factor and one with group (referring to classification according to ADHD/subthreshold ADHD or existence of milder attention-related problems) as a between-subject factor. Both analyses were considered to fulfill the sphericity assumption (Mauchly's $\mathrm{W}=0.984$, $\mathrm{df}=2, P=0.216$ and Mauchly's $\mathrm{W}=0.987$, $\mathrm{df}=2, P=0.288$, respectively).

The first and second studies had been approved by the regional ethical review board in Stockholm and had been performed in accordance with the tenets of the Declaration of Helsinki; the third study had been performed within a quality project being undertaken among schools in Stockholm.

\section{Results}

A $2 \times 3$ analysis of variance with gender as a betweensubject factor, type of index (general ability index, freedom from distractibility index, and processing speed index) as a within-subject factor, and index score as the dependent variable, revealed a main effect relating to the type of index $\left(F_{2,392}=18.06, P<0.001, \eta_{\text {partial }}^{2}=0.084\right)$ and indicating that the children performed differently on the three indices. As can be seen in Figure 1, performance was considerably higher on the general ability index than on the two other indices. This was also confirmed with pairwise comparisons using the Bonferroni method to adjust for multiple comparisons $(P<0.001$ for the difference between general ability index and freedom from distractibility index as well as for the difference between general ability index and processing speed index, but the difference between freedom from distractability index and processing speed index was not significant). Moreover, the differences between the indices were more pronounced for boys, as revealed by a significant gender $\times$ type of index interaction effect $\left(F_{2,392}=4.07\right.$, $\left.P=0.018, \eta_{\text {partial }}^{2}=0.020\right)$. It can also be seen in Figure 1 that the mean scores for all indices and for both boys and girls were significantly below 100 (ie, the mean for the general population).

The main effect of type of index was maintained when comparing pupils having ADHD/subthreshold ADHD with those having milder attention problems rather than gender in a $2 \times 3$ analysis of variance $\left(F_{2,390}=25.87, P<0.001\right.$, 


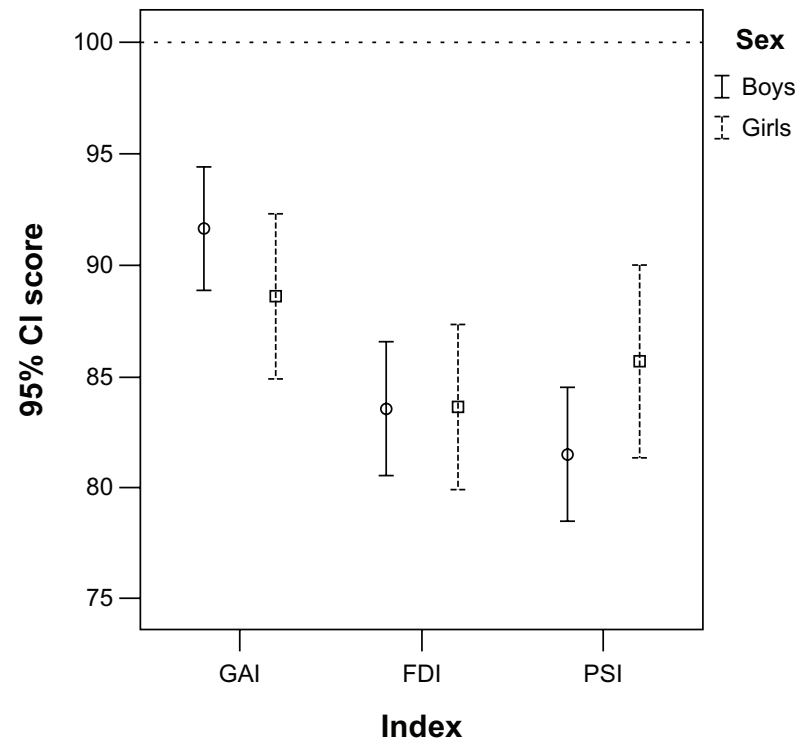

Figure I Mean index scores with $95 \%$ confidence intervals for the three indices (GAI, FDI, and PSI) and for boys and girls.

Abbreviations: $\mathrm{Cl}$, confidence interval; GAI, general ability index; FDI, freedom from distractibility index; PSI, processing speed index.

$\eta_{\text {partial }}^{2}=0.12$ ). As can be seen in Figure 2, the two groups had very similar scores on the general ability index and on the freedom from distractibility index, but on the processing speed index the children with ADHD/subthreshold ADHD performed slightly worse than the children with relatively mild attention problems. However, the group $\times$ type of index interaction was not significant $\left(F_{2,390}=2.77, P=0.064\right.$, $\left.\eta_{\text {partial }}^{2}=0.014\right)$.

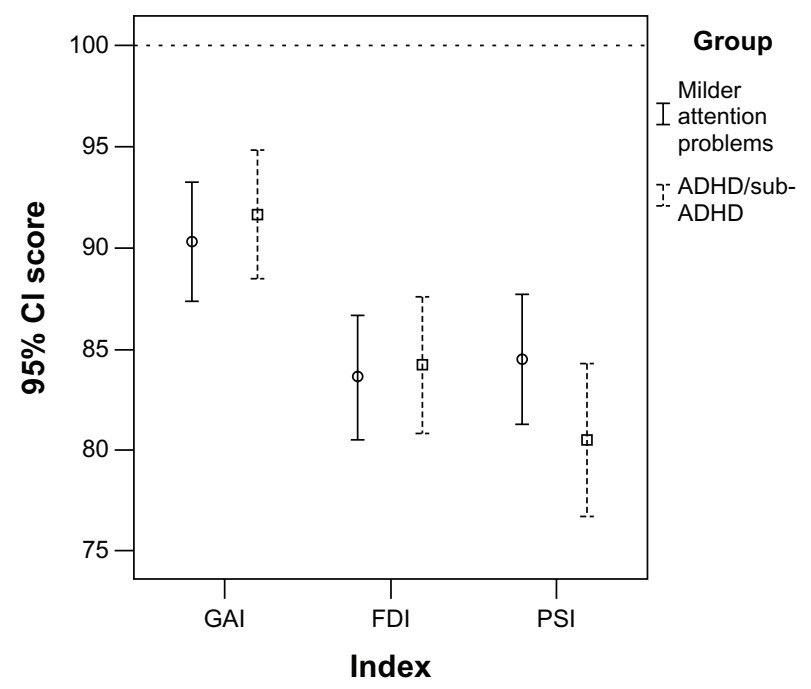

Figure 2 Mean index scores with 95\% confidence intervals for the three indices (GAI, FDI, and PSI) and for children with mild attention problems versus children with ADHD/subthreshold ADHD.

Abbreviations: ADHD, attention deficit hyperactivity disorder; $\mathrm{Cl}$, confidence interval; GAI, general ability index; FDI, freedom from distractibility index; PSI, processing speed index.
The reason for not using one single $2 \times 2 \times 3$ analysis of variance with gender and group as between-subject factors and type of index as a within-subject factor was that this would lead to very different numbers in the different cells (ranging from 20 girls with ADHD/subthreshold ADHD to 80 boys with milder attention problems). When we performed such an analysis (disregarding the violation of the analysis of variance assumptions in so doing) we obtained the same results.

\section{Discussion}

Our main findings from this relatively large group of school children with different degrees and severity of attention difficulties were that all cognitive indices were significantly below 100, and the general ability index significantly exceeded the freedom from distractibility index and processing speed index. This pattern was evident in both the ADHD/ subthreshold ADHD group and in the group with milder attention problems, and the difference between the indices was especially pronounced in boys.

Executive deficits, demonstrated as low processing speed and low verbal working memory capacity, have been reported in many neurodevelopmental groups, including in individuals with autism spectrum disorders, language impairment, borderline intellectual functioning, and intellectual/learning disability, but above all in individuals with ADHD. ${ }^{7,25-28}$

In our study, the group was heterogeneous and comprised pupils previously assessed in three different studies, the common denominator being that all of those included in the investigations had had learning, behavior and attention difficulties in school. One subgroup (comprising approximately one third of the total group) met the criteria for ADHD/ subthreshold ADHD and the other subgroup (approximately two thirds of the total group) consisted of children who had relatively mild attention problems, but did not meet the criteria for ADHD or subthreshold ADHD. The two groups exhibited the same cognitive pattern, with significantly lower verbal working memory and processing speed indices than one would expect for their overall intellectual ability. Thus, the discrepancy was also evident in children with less pronounced attention problems, indicating that the finding might also be valid in the large group of children with subclinical problems that are not regularly identified. Not all children who underperform at school have the degree of difficulty associated with a diagnostic label, and these pupils run the risk of not being properly identified and, consequently, of not having their cognitive deficits recognized and addressed. Our results indicate that the same cognitive deficits can be 
found in pupils with relatively mild attention problems and are in accordance with those of Cabral. ${ }^{29}$ Cabral pointed out that ADHD is on a spectrum, with milder attention deficit/ hyperactivity problems, and that boundaries with regard to "normality" are blurred.

This view was also corroborated in our previous study, in which we could demonstrate that children with ADHD and those with behavioral, learning, and milder attention problems at the age of 10-11 years had a significantly lower mean grade than a comparison group when finishing compulsory schooling at the age of 16 years. ${ }^{3}$

The findings of the present study underscore this finding and broaden the scope concerning executive problems or weaknesses. In children with learning difficulties, a cognitive evaluation will often be helpful in explaining underachievement in a demanding classroom situation. The ideology of today's schools in many parts of the world is inclusion, but the more subtle types of learning difficulties may not be recognized in inclusive settings. In particular, a low processing speed is especially difficult to pin down, for teachers, parents, and pupils themselves. It is important to recognize the group comprised of those with relatively mild learning and attention-related problems at school because their general cognitive capacity may mask their executive difficulties.

The interplay between working memory and processing speed has been studied, and it has been reported that processing speed strongly influences working memory. A faster processing speed makes it possible to process more information in less time, so the functional capacity of working memory increases. ${ }^{30}$

The present study has certain limitations. Although the three clinical groups are heterogeneous with regard to age group, sample size, and inclusion criteria, they represent school children with clinically evident learning, attention, and behavior problems, reported by teachers, parents, and in most cases, by the pupils themselves. We consider that the heterogeneity could also be a strength of the study, because we were able to include a group of children with relatively mild subclinical problems, and this latter group is not generally recognized and included.

Executive function is a broad concept, including several different aspects. In this study, executive function was expressed only by two of the WISC-III indices, giving a narrow interpretation of executive function.

In conclusion, the results indicate the importance of paying attention to cognitive factors in children with different kinds of learning and attention-associated problems. This is true for those presenting with an average general IQ, but with relatively mild attention-related problems, as well as for those with problems of sufficient severity to warrant a clinical diagnosis.

\section{Acknowledgment}

Financial support for this research was obtained from the Center for Competence in Care, based at Stockholm University.

\section{Disclosure}

The authors report no conflicts of interest in this work.

\section{References}

1. Kaufman AS. Intelligent Testing with the WISC III. New York, NY: Wiley; 1994.

2. Smedler AC, Törestad B. Verbal intelligence: a key to basic skills. Educ Stud. 1996;22:343-355

3. Ek U, Westerlund J, Holmberg K, Fernell E. Academic performance of adolescents with ADHD and other behavioural and learning problems a population-based longitudinal study. Acta Paediatr. 2011;100: 402-406.

4. Foley J, Garcia J, Shaw L, Golden C. IQ predicts neuropsychological performance in children. Int J Neurosci. 2009;119:1830-1847.

5. Geary DC. Cognitive predictors of achievement growth in mathematics: a 5-year longitudinal study. Dev Psychol. 2011;47:1539-1552.

6. Saklofske DH, Prifitera A, Weiss LG, Rolfhus E, Zhu J. Clinical interpretation of the WISC-IV FSIQ and GAI. In: Prifitera A, Saklofske DH, Weiss LG, editors. WISC-IV Clinical Use and Interpretation: Scientist-Practitioner Perspectives. New York, NY: Academic Press; 2005.

7. Pennington BF, Ozonoff S. Executive functions and developmental psychopathology. J Child Psychol Psychiatry. 1996;37:51-87.

8. Rucklidge JJ, Tannock R. Neuropsychological profiles of adolescents with ADHD: effects of reading difficulties and gender. $J$ Child Psychol Psychiatry. 2002;43:988-1003.

9. Gropper RJ, Tannock R. A pilot study of working memory and academic achievement in college students with ADHD. J Atten Disord. 2009; 12:574-581.

10. Zander E, Dahlgren SO. WISC-III index score profiles of 520 Swedish children with pervasive developmental disorders. Psychol Assess. 2010;22:213-222.

11. Montgomery JW, Windsor J. Examining the language performances of children with and without specific language impairment: contributions of phonological short-term memory and speed of processing. $J$ Speech Lang Hear Res. 2007;50:778-797.

12. Alloway TP. Working memory and executive function profiles of individuals with borderline intellectual functioning. J Intellect Disabil Res. 2010;54:448-456.

13. Danielsson H, Henry L, Messer D, Rönnberg J. Strengths and weaknesses in executive functioning in children with intellectual disability. Res Dev Disabil. 2012;33:600-607.

14. Jacobson LA, Ryan M, Martin RB, et al. Working memory influences processing speed and reading fluency in ADHD. Child Neuropsychol. 2011;17:209-224.

15. Katz LJ, Brown FC, Roth RM, Beers SR. Processing speed and working memory performance in those with both ADHD and a reading disorder compared with those with ADHD alone. Arch Clin Neuropsychol. 2011;26:425-433.

16. Swanson HL, Sachse-Lee C. Mathematical problem solving and working memory in children with learning disabilities: both executive and phonological processes are important. J Exp Child Psychol. 2001;79: 294-321. 
17. Mayes SD, Calhoun SL. Learning, attention, writing and processing speed in typical children and children with ADHD, autism, anxiety, depression and oppositional-defiant disorder. Child Neuropsychol. 2007;13:469-493.

18. Ek U, Fernell E, Westerlund J, Holmberg K, Olsson PO, Gillberg C. Cognitive strengths and deficits in schoolchildren with ADHD. Acta Paediatr. 2007;96:756-761.

19. Ek U, Norrelgen F, Westerlund J, Dahlman A, Hultby E, Fernell E. Teenage outcomes after speech and language impairment at preschool age. Neuropsychiatr Dis Treat. 2012;8:221-227.

20. Ek U, Westerlund J, Furmark C, Fernell E. An audit of teenagers who had not succeeded in elementary school: a retrospective case review. Clinical Audit. 2012;4:1-7.

21. Wechsler D. Wechsler Intelligence Scale for Children, 3rd ed. New York, NY: Psychological Corporation; 1999.

22. Prifitera A, Weiss LG, Saklofske DH. The WISC-III in context. In: Prifitera A, Saklofske DH, editors. WISC-III Clinical Use and Interpretation: Scientist Practitioner Perspectives. New York, NY: Academic Press; 1998.

23. American Psychiatric Association. Diagnostic and Statistical Manual of Mental Disorders. Fourth Edition. Washington, DC: American Psychiatric Association; 1994.
24. American Academy of Pediatrics. Diagnostic and Statistical Manual of Mental Disorders for Primary Care. Washington, DC: American Academy of Pediatrics; 1997.

25. Friedman NP, Haberstick BC, Willcutt EG, et al. Greater attention problems during childhood predict poorer executive functioning in late adolescence. Psychol Sci. 2007;18:893-900.

26. Miniscalco C, Hagberg B, Kadesjö B, Westerlund M, Gillberg C. Narrative skills, cognitive profiles and neuropsychiatric disorders in 7-8-year-old children with late developing language. Int J Lang Commun Disord. 2007;42:665-681.

27. Mayes SD, Calhoun SL. WISC-IV and WIAT-II profiles in children with high-functioning autism. J Autism Dev Disord. 2008;38:428-439.

28. Thaler NS, Bello DT, Etcoff LM. WISC-IV profiles are associated with differences in symptomatology and outcome in children with ADHD. J Atten Disord. January 27, 2012. [Epub ahead of print.]

29. Cabral P. Attention deficit disorders: are we barking up the wrong tree? Eur J Paediatr Neurol. 2006;10:66-77.

30. Swanson HL, Howard CB, Sáez L. Do different components of working memory underlie different subgroups of reading disabilities? J Learn Disabil. 2006;39:252-269.
Neuropsychiatric Disease and Treatment

\section{Publish your work in this journal}

Neuropsychiatric Disease and Treatment is an international, peerreviewed journal of clinical therapeutics and pharmacology focusing on concise rapid reporting of clinical or pre-clinical studies on a range of neuropsychiatric and neurological disorders. This journal is indexed on PubMed Central, the 'PsycINFO' database and CAS.

\section{Dovepress}

The manuscript management system is completely online and includes a very quick and fair peer-review system, which is all easy to use. Visit http://www.dovepress.com/testimonials.php to read real quotes from published authors. 